\title{
Letter to the Editor in Response to: COVID-19: Magnifying the Effect of Health Disparities
}

J Gen Intern Med 35(9):2780

DOI: $10.1007 / \mathrm{s} 11606-020-06038-\mathrm{z}$

(c) Society of General Internal Medicine 2020

$\mathrm{T}$ he recent article by Kim et al. highlighted the disproportionate impact of the coronavirus disease 19 (COVID-19) pandemic on lower income and racial minorities in the USA. ${ }^{1}$ The authors discuss how greater comorbidities, less access to medical care, and financial challenges markedly worsened the incidence and severity of COVID-19 in certain disadvantaged groups. Detailed racial data released by public agencies in New York further demonstrates the stark disparities of the pandemic.

The New York City (NYC) Department of Health and Mental Hygiene reported 19,540 confirmed or probable deaths from COVID-19 among NYC residents as of May 6, 2020. Ageadjusted (per 100,000) death rates among African Americans and Latinos were 243.6 and 237.7, respectively, in contrast to death rates among Whites and Asians that were 121.5 and 109.4, respectively. ${ }^{2}$ Data from NYC reported by the New York State Department of Health demonstrated that Latinos comprised $34 \%$ of COVID-19 deaths but $29 \%$ of the population and African Americans comprised 28\% of deaths while making up $22 \%$ of the population. ${ }^{3}$ In contrast, Whites comprised $27 \%$ of deaths while representing $32 \%$ of the population.

To date, there remains a relative paucity of racial mortality data from individual hospitals in NYC. Two of the largest hospital systems published early clinical outcomes, but both series contained over 37\% White patients which may not accurately reflect the experience of lower income, minority communities. ${ }^{4}{ }^{5}$ To our knowledge, the NYC Health and Hospitals Corporation which cares for the largest number of minorities has not publicly released race-specific mortality data.

It is noteworthy that the best available data has come directly from governmental agencies in a timely fashion through both daily press briefings and well-organized websites. We commend the political leadership in New York for this effort and are keenly aware that not all states have been as transparent. The rapid dissemination of health information has

Received May 19, 2020

Accepted July 3, 2020

Published online July 14, 2020 been critical in allowing the public to grasp the sheer magnitude of the crisis and objectively highlight the hardest-hit zip codes and racial groups.

As we consider ways to safely reopen, it is critical that the latest data continue to be openly disseminated to best understand the causes of racial disparities and direct recovery efforts towards communities that bear the greatest burden of disease. This will require government agencies to continue to publicize accurate pandemic statistics and individual hospitals to prioritize sharing their unique experiences.

Mariela Martinez, M.D. M.S. ${ }^{1}$

Michael Silver, M.S. ${ }^{2}$

Ariel Schulman, M.D. ${ }^{1}$

${ }^{1}$ Division of Urology, Maimonides Medical Center, Brooklyn, NY, USA

${ }^{2}$ Department of Medicine, SUNY Downstate Medical Center, Brooklyn, NY, USA,

Corresponding Author: Mariela Martinez, M.D. M.S.; Division of Urology, Maimonides Medical Center, Brooklyn, NY, USA (e-mail: mmrivera@maimonidesmed.org).

\section{Compliance with Ethical Standards:}

Conflict of Interest: The authors declare that they do not have a conflict of interest.

\section{REFERENCES}

1. Kim EJ, Marrast L, Conigliaro J. COVID-19: magnifying the effect of health disparities. J Gen Intern Med. 2020 May 11:1-2. doi: https://doi. org/10.1007/s11606-020-05881-4.

2. New York City Health COVID-19: Data [Internet]. New York: New York City Department of Health and Mental Hygiene; c2020 [cited 2020 May 13]. Available from: https://wwwl.nyc.gov/site/doh/covid/covid-19-data.page

3. New York State Department of Health COVID-19 Tracker [Internet] New York State Department of Health. c2020 [cited 2020 May 13] Available from: https://covid19tracker.health.ny.gov.

4. Goyal P, Choi JJ, Pinheiro LC, Schenck EJ, et al. Clinical characteristics of COVID-19 in New York City. N Engl J Med. 2020 Apr 17: NEJMc2010419. doi: https://doi.org/10.1056/NEJMc2010419.

5. Richardson S, Hirsch JS, Narasimhan M, et al. Presenting characteristics, comorbidities, and outcomes among 5700 patients hospitalized with COVID-19 in the New York City area. JAMA. 2020 Apr 22: e206775. doi: https://doi.org/10.1001/jama.2020.6775

Publisher's note Springer Nature remains neutral with regard to jurisdictional claims in published maps and institutional affiliations. 